\title{
C-Reactive Protein to Prealbumin Ratio (CPR): A Novel Inflammatory-Nutritional Prognostic Factor for Predicting Cancer-Specific Survival (CSS) and Overall Survival (OS) in Patients with Resectable Esophageal Squamous Cell Carcinoma
}

\author{
Ji-Feng Feng $\mathbb{D},{ }^{1,2}$ Liang Wang, ${ }^{1}$ You-Hua Jiang, ${ }^{1}$ and Xun Yang $\mathbb{D}^{1,2}$ \\ ${ }^{1}$ Department of Thoracic Oncological Surgery, Institute of Cancer Research and Basic Medical Sciences of Chinese Academy of Sciences, \\ Cancer Hospital of University of Chinese Academy of Sciences, Zhejiang Cancer Hospital, No.38 Guangji Road, \\ Hangzhou 310022, China \\ ${ }^{2}$ Key Laboratory Diagnosis and Treatment Technology on Thoracic Oncology, No. 38 Guangji Road, Zhejiang Province, \\ Hangzhou 310022, China
}

Correspondence should be addressed to Ji-Feng Feng; fengjif@163.com and Xun Yang; xunyangzj@sina.com

Received 2 April 2019; Accepted 16 June 2019; Published 14 July 2019

Guest Editor: Philippe-Richard J. Domeyer

Copyright (c) 2019 Ji-Feng Feng et al. This is an open access article distributed under the Creative Commons Attribution License, which permits unrestricted use, distribution, and reproduction in any medium, provided the original work is properly cited.

Background. The inflammation and nutrition play an important role in prognosis. A novel index combined with inflammatory and nutritional biomarkers, named C-reactive protein (CRP) to prealbumin (PALB) ratio (CPR), was initially reported to predict the prognosis in resectable esophageal squamous cell carcinoma (ESCC). Patients and Methods. A retrospective study was conducted including 346 resectable ESCC patients. The X-tile program was used to confirm the optimal cut-off value. The Kaplan-Meier methods and Cox regression analyses were performed to analyze the cancer-specific survival (CSS) and overall survival (OS). Results. The optimum cut-off point was 0.03 for CPR. Patients with a high level of CPR $(>0.03)$ were associated with poor CSS $(12.0 \%$ vs. $43.0 \%, P<0.001)$ and $O S(11.2 \%$ vs. $40.7 \%, P<0.001)$. Multivariate analyses revealed that $\mathrm{CPR}$ was an independent predictor in resectable ESCC patients (CSS, $P=0.008$; OS, $P=0.007$ ). Conclusion. This study, to the best of our knowledge, is the first to investigate prognostic role of CPR in patients with ESCC. Our retrospective observations indicate that CPR, with the optimal cut-off value of 0.03 , is a useful potential predictor in resectable ESCC patients.

\section{Introduction}

Esophageal cancer (EC) is one of the prevalent cancers worldwide, whose incidences vary widely in different countries and regions, with approximately $53.8 \%$ and $51.9 \%$ of all ECs occurring and dying in China [1]. The major kind of pathological type (90\%-95\%) is esophageal squamous cell carcinoma (ESCC) in China [2,3]. Radical esophagectomy remains the most effective therapy for patients with EC. However, the prognosis for EC remains poor $[4,5]$. Therefore, it is very important to find more and more useful and effective prognostic indicators for patients with EC.

The inflammation and nutrition are associated with cancer prognosis [6]. As the most sensitive inflammatory biomarker, C-reactive protein (CRP) has been confirmed in a series of cancers to predict the prognosis, including EC [79]. Albumin (ALB) is an important nutritional biomarker. Several studies over the past few years have revealed that ALB serves as a prognostic factor for predicting prognosis in patients with EC $[10,11]$. Over the recent years, a new index (combined with inflammatory and nutritional biomarkers) named CRP to ALB ratio (CAR) was reported to predict the prognosis for patients with EC $[12,13]$. Additionally, recent studies reported that prealbumin (PALB), serving as another important biomarker for nutritional status, is more sensitive to malnutrition than ALB $[14,15]$.

It is commonly recognized that CRP and PALB are both cheap and simple serum biomarkers which could be 
conducted in daily clinical practices. However, to our knowledge, no study has assessed the prognostic role of CPR (CRP/PALB ratio) in ESCC patients so far. Thus, the aim of our study was initially to explore the prognostic role of CPR for predicting prognosis with the optimal cut-off value in resectable ESCC patients.

\section{Patients and Methods}

2.1. Patients. From January 2007 to December 2010 in the Department of Thoracic Oncological Surgery, a retrospective study involving 346 resectable ESCC patients was conducted, along with the confirmation of levels of serum CRP, ALB, and PALB one week before surgery. Patients who received preoperative treatment, such as chemotherapy and/or radiotherapy, those who suffered from any form of inflammatory diseases or infections (acute or chronic) or systemic diseases, and those diagnosed with distant metastases were excluded. Written informed consent for the collection of specimen and other medical information were obtained from all patients before surgery. The current study was approved by the Ethics Committees of Zhejiang Cancer Hospital (IRB Approval No. IRB-2018-130).

2.2. Treatment and Follow-Up. The standard esophagectomy includes the Ivor Lewis procedure (for patients with ESCC in the middle or lower third) and McKeown procedure (for patients with ESCC in the upper third) [16, 17]. The twofield thoracoabdominal lymphadenectomy was the major method of lymphadenectomy [18]. Follow-up was performed in regular intervals, and the follow-up results were obtained through reviews of the hospital records and outpatient visit.

2.3. Data Collection. The main clinical characteristics, such as age, gender, tumor length and location, vessel invasion, differentiation, TNM stage, and serum CRP, ALB, and PALB, were collected in our medical records. The TNM stage in this study was in accordance with the 7th AJCC/UICC TNM staging system [19]. The levels of CRP, ALB, and PALB were obtained within one week before surgery. CAR was defined as $\mathrm{CRP}$ to $\mathrm{ALB}$ ratio. CPR was defined as CRP to PALB ratio. The data used to support the findings of this study are included within the article.

2.4. Statistical Analysis. The X-tile program was performed to calculate the optimum cut-off points for CRP, ALB, PALB, CAR, and CPR [20]. The chi-squared test was utilized to analyze the clinical characters grouped by CPR. Besides, the Kaplan-Meier method and Cox regression analyses were utilized to analyze the cancer-specific survival (CSS) and overall survival (OS). The areas under the curve (AUC) for CPR, CAR, CRP, ALB, and PALB were calculated and compared by the receiver operating characteristic (ROC) curve. Statistical analyses were conducted with SPSS 20.0 (SPSS Inc., Chicago, IL, USA) and MedCalc 15.2 (MedCalc Software bvba, Ostend, Belgium).

\section{Results}

3.1. Patient Characteristics. There were 76 (22.0\%) women and $270(78.0 \%)$ men in all 346 patients. The mean values for CRP, ALB, PALB, CAR, and CPR were $8.55 \pm 12.18 \mathrm{mg} / \mathrm{L}$ (range 0.10-107.34 mg/L), $40.3 \pm 5.3 \mathrm{~g} / \mathrm{L}$ (range 26.6-52.4 g/L), $260 \pm 65 \mathrm{mg} / \mathrm{L}$ (range 126-426 mg/L), $0.22 \pm 0.34$ (range $0.002-2.670$ ), and $0.0365 \pm 0.0539$ (range 0.0003-0.4993), respectively. The optimum cut-off points according to the X-tile program for CRP, ALB, PALB, CAR, and CPR were $10.5 \mathrm{mg} / \mathrm{L}, 40.5 \mathrm{~g} / \mathrm{L}, 248 \mathrm{mg} / \mathrm{L}, 0.3$, and 0.03 , respectively (Figure 1).

Patients then were divided into two groups (high and low group) for further analyses $(C P R \leq 0.03$ and $C P R>0.03)$. The clinicopathologic characters regarding $\mathrm{CPR}$ and other clinical characters were shown in Table 1. Compared with the patients with $\mathrm{CPR} \leq 0.03$, patients with the $\mathrm{CPR}>0.03$ had even closer association with vessel invasion $(P=0.025)$, TNM stage $(P=0.035)$, and other indices (CRP, $P<0.001$; ALB, $P=0.037$; PALB, $P<0.001$; CAR, $P<0.001)$.

The mean values grouped by TNM stage for CPR were $0.0278 \pm 0.0421,0.0343 \pm 0.0398$, and $0.0437 \pm 0.0680$, respectively, with significant differences between TNM I and TNM III $(P=0.030)$, but no significant differences regarding the CPR were found between the TNM I and TNM II $(P=0.386)$ and TNM II and TNM III $(P=0.166)$ (Figure $2(\mathrm{a}))$. Negative correlations between CRP and ALB $(r=-0.166$, $P=0.002$, Figure 2(b)) and CRP and PALB $(r=-0.134$, $P=0.013$, Figure 2(c)), respectively, and positive correlations between ALB and PALB ( $r=0.119, P=0.027$, Figure $2(\mathrm{~d}))$ were found in our study.

3.2. Cancer-Specific Survival and Overall Survival Analyses. Patients with a high level of CPR $(>0.03)$ were associated with poor CSS $(P<0.001)$. To be more specific, the 5 -year CSS was $12.0 \%$ in patients with CPR $>0.03$ and $43.0 \%$ in those with $C P R \leq 0.03$ (Figure 3(a)). It was revealed in subgroup analyses based on TNM stage that CPR was also significantly associated with CSS (Figures 3(b)-3(d)). The 5-year CSS were also significantly different for patients grouped by CRP (39.6\% vs. $11.5 \%, P<0.001)$, ALB $(25.1 \%$ vs. $38.9 \%, P=0.002)$, PALB $(21.7 \%$ vs. $40.5 \%, P<0.001)$, and CAR $(39.0 \%$ vs. $5.4 \%, P<0.001)$ (Figures $3(\mathrm{e})-3(\mathrm{~h})$ ). Patients with a high level of CPR $(>0.03)$ were associated with poor OS (11.2\% vs. $40.7 \%, P<0.001)$ (Figure $4(\mathrm{a})$ ). It was revealed that CPR was also significantly correlated with OS in the subgroup analyses based on TNM stage (Figures 4(b)-4(d)).

3.3. Cox Regression Analyses. It is generally recognized that several factors, such as tumor length, vessel invasion, CRP, ALB, PALB, CAR, CPR, and TNM stage, were significantly associated with CSS in univariate analyses (Table 2). However, we found that $\mathrm{CPR}(\mathrm{HR}=1.630, P=0.008)$ was an independent predictor for CSS in multivariate analyses (Table 2). Multivariate analyses regarding OS in patients with ESCC were also performed. It was revealed that CPR was also an independent predictor (Table 3). 

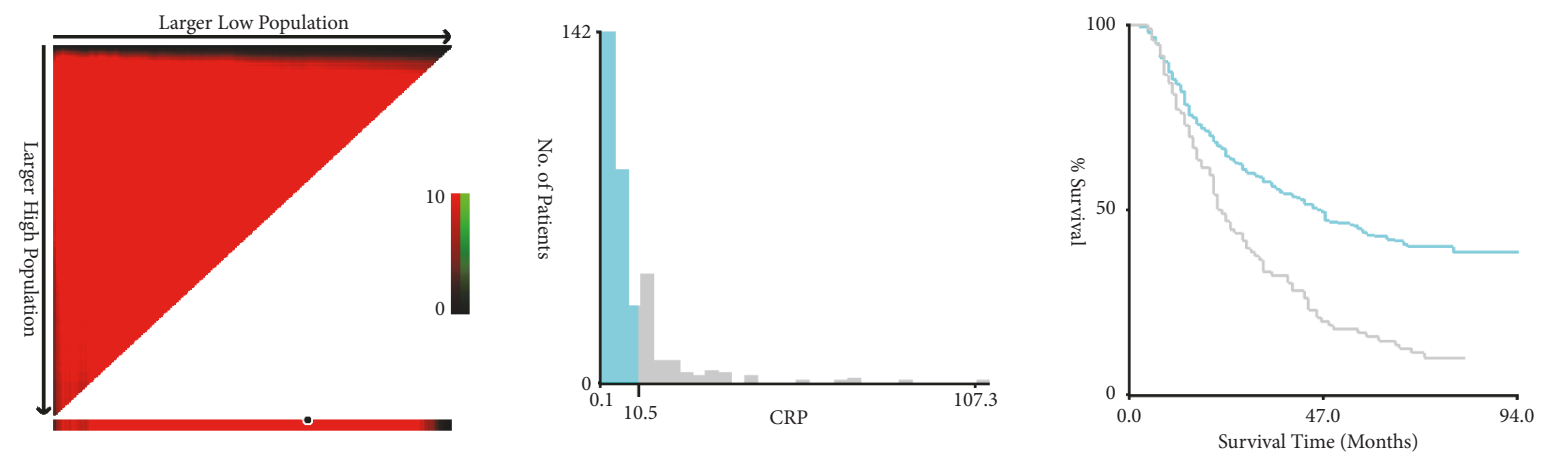

(a)
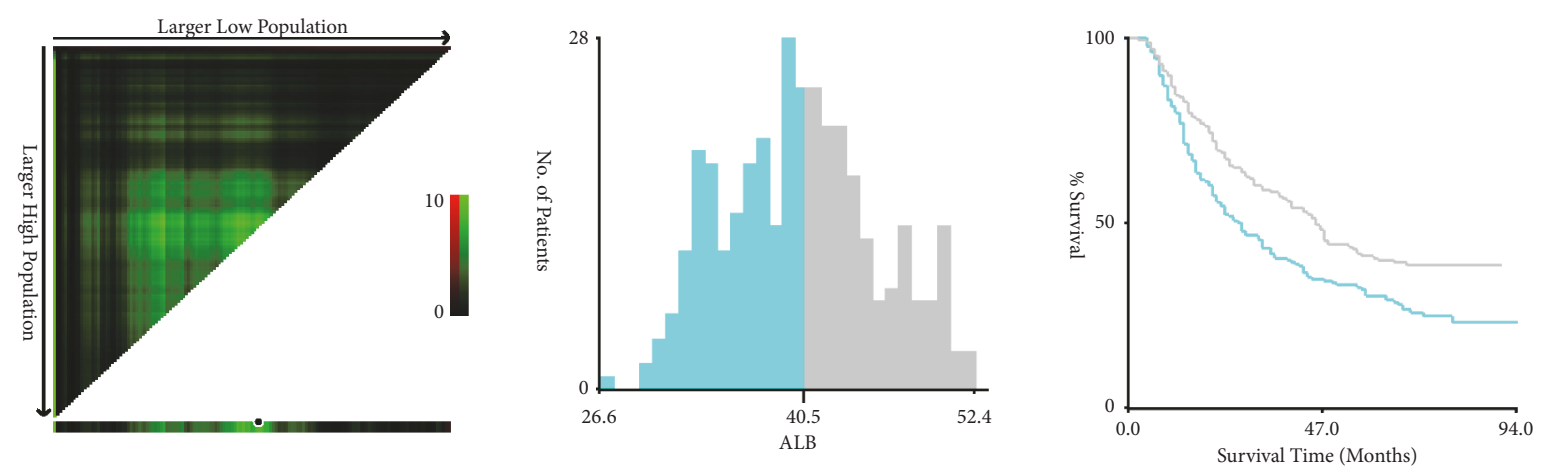

(b)
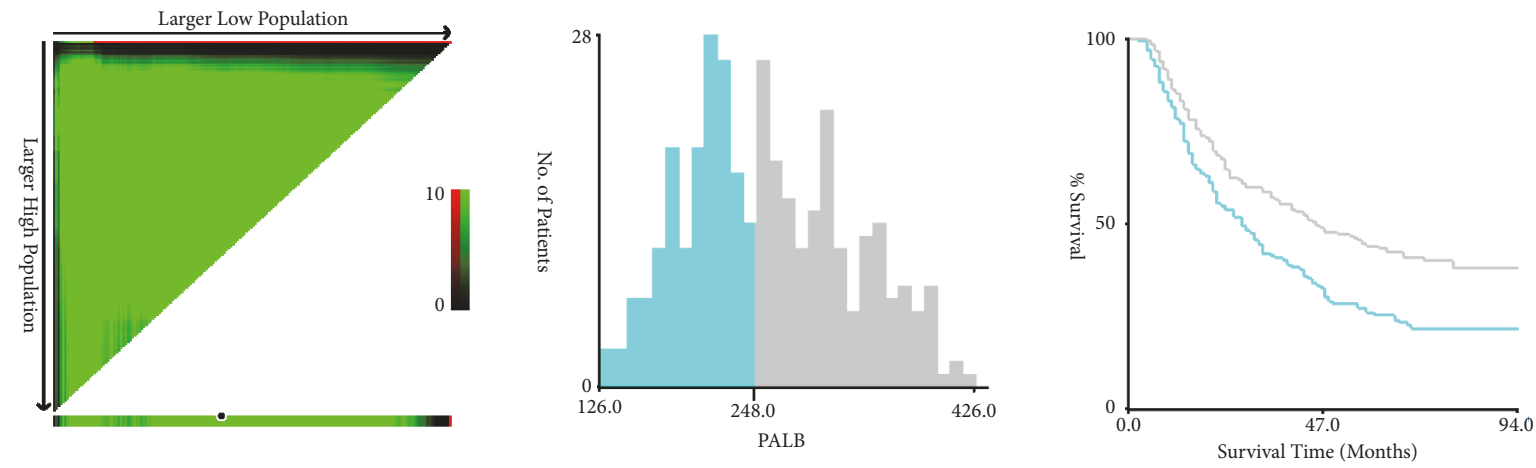

(c)
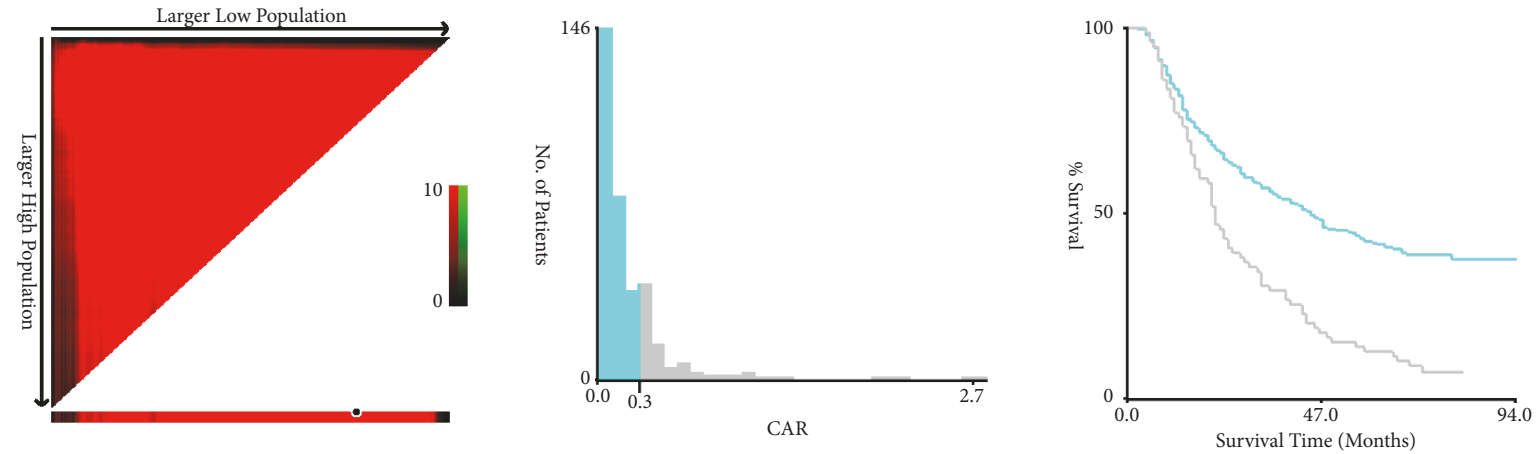

(d)

Figure 1: Continued. 

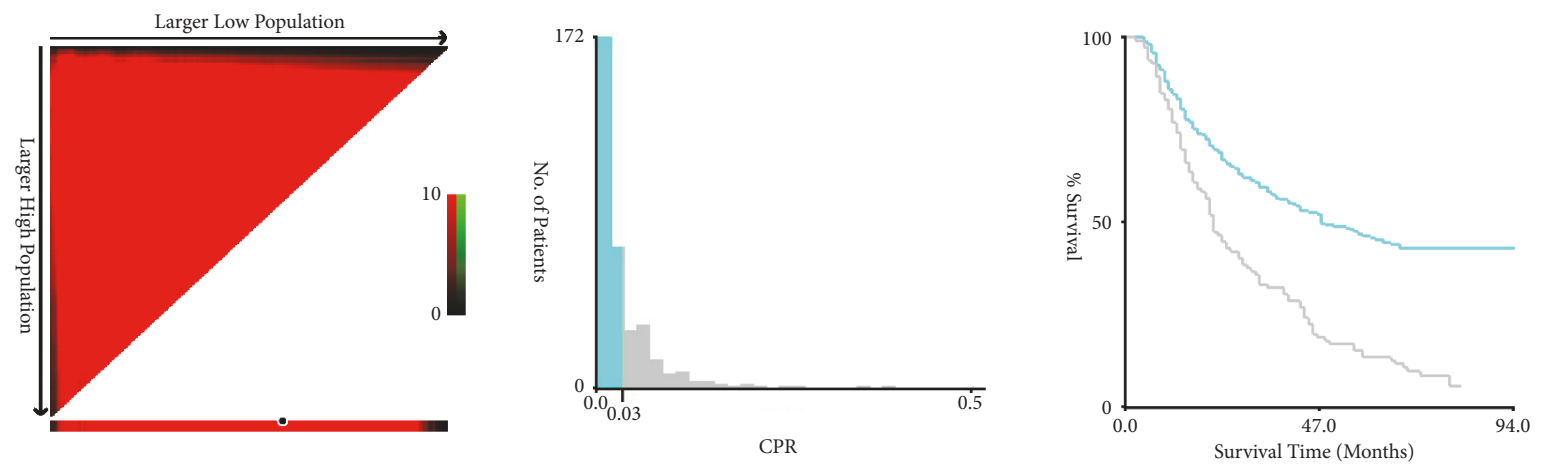

(e)

FIGURE 1: X-tile analyses. The optimum cut-off points according to the X-tile program for CRP (a), ALB (b), PALB (c), CAR (d), and CPR (e) were $10.5 \mathrm{mg} / \mathrm{L}, 40.5 \mathrm{~g} / \mathrm{L}, 248 \mathrm{mg} / \mathrm{L}, 0.3$, and 0.03 , respectively.

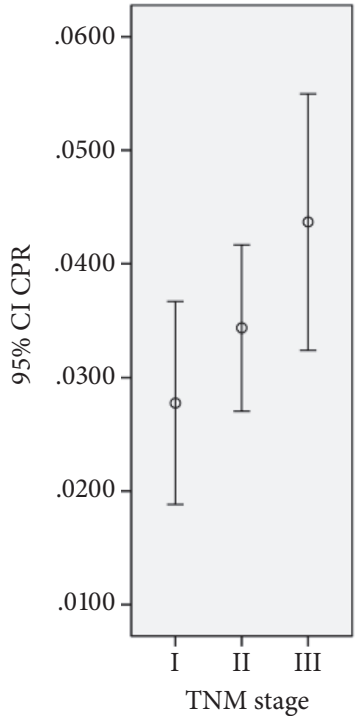

(a)

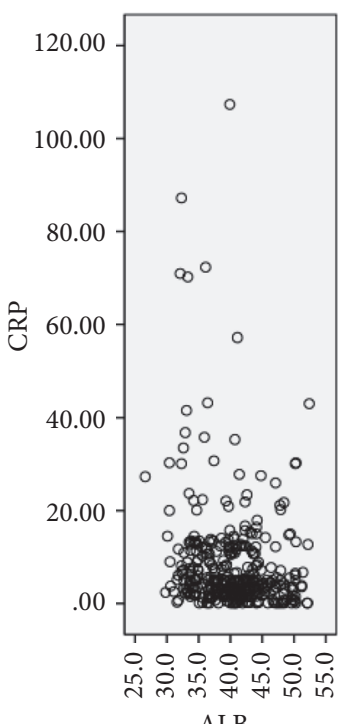

(b)

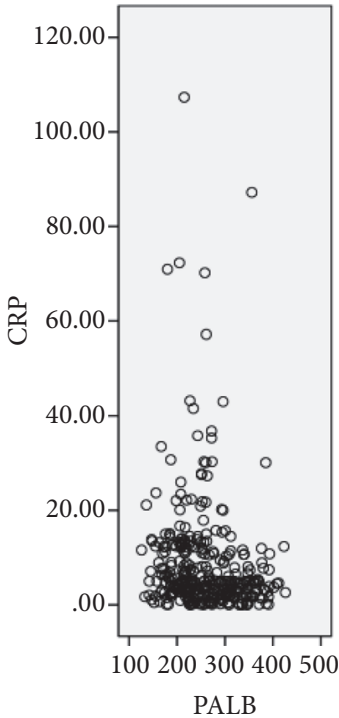

(c)

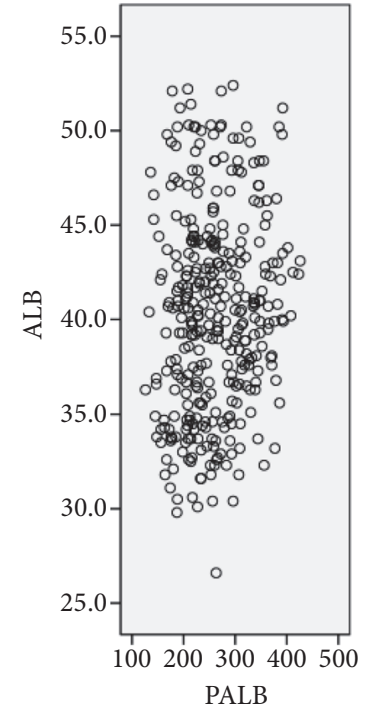

(d)

FIGURE 2: Significant differences were found between TNM I and TNM III ( $\mathrm{P}=0.030)$ (a). Negative correlations between CRP and ALB (b) and CRP and PALB (c), respectively, and positive correlations between ALB and PALB (d) were found.

3.4. ROC Analyses. The AUC area of the CPR (0.728, 95\% CI: $0.678-0.774)$ was higher than that of CAR $(0.702,95 \%$ CI: 0.651-0.750), CRP (0.702, 95\% CI: 0.651-0.750), ALB (0.573, 95\% CI: 0.519-0.625), and PALB (0.686, 95\% CI: 0.6350.735 ) for all the ESCC patients (Figure 5). Comparison of AUC areas for the prognostic factors in ESCC was shown in Table 4.

\section{Discussion}

To the best of our knowledge, this is the first study to investigate the prognostic role of CPR in patients with ESCC. Our study demonstrated some important findings: (1) CPR was a strong predictor of CSS and OS; (2) CPR, instead of CAR, CRP, ALB, or PALB, was a useful independent predictive indicator.

Related studies have shown that the presence of systematic inflammatory response and malnutrition are responsible for the poor prognosis in patients with cancers $[6,21]$. CRP is the most sensitive inflammatory biomarker. However, the prognostic role of CRP remains controversial in EC $[9,22]$. It was revealed in a meta-analysis conducted by us recently that CRP was significantly associated with overall survival in EC [23]. Recent published studies have reported that ALB was a nutritional factor, which reflected the nutritional status in several cancers, including EC $[10,11]$. Furthermore, $\mathrm{Xu}$ et al. [12] and Wei et al. [13] reported that CAR is significantly associated with the prognosis in ESCC patients $[12,13]$. Significant differences for patients grouped by CRP 
TABLE 1: Comparison of baseline clinical characteristics based on CPR in ESCC.

\begin{tabular}{|c|c|c|c|c|}
\hline \multirow{3}{*}{ Age (years) } & \multirow{2}{*}{ Cases (n, \%) } & \multicolumn{2}{|c|}{$\mathrm{CPR}$} & \multirow{2}{*}{ P-value } \\
\hline & & $\leq 0.03(\mathrm{n}, \%)$ & $>0.03(\mathrm{n}, \%)$ & \\
\hline & & & & 0.108 \\
\hline$\leq 60$ & $199(57.5)$ & $120(54.3)$ & $79(63.2)$ & \\
\hline$>60$ & $147(42.5)$ & $101(45.7)$ & $46(36.8)$ & \\
\hline Gender & & & & 0.077 \\
\hline Female & $76(22.0)$ & $42(19.0)$ & $34(27.2)$ & \\
\hline Male & $270(78.0)$ & $179(81.0)$ & $91(72.8)$ & \\
\hline Tumor length $(\mathrm{cm})$ & & & & 0.242 \\
\hline$\leq 3.0$ & $96(27.7)$ & $66(29.9)$ & $30(24.0)$ & \\
\hline$>3.0$ & $250(72.3)$ & $155(70.1)$ & $95(76.0)$ & \\
\hline Tumor location & & & & 0.179 \\
\hline Upper & $18(5.2)$ & $11(5.0)$ & $7(5.6)$ & \\
\hline Middle & $164(47.4)$ & $97(43.9)$ & $67(53.6)$ & \\
\hline Lower & $164(47.4)$ & $113(51.1)$ & $51(40.8)$ & \\
\hline Vessel invasion & & & & 0.025 \\
\hline Negative & $289(83.5)$ & $192(86.9)$ & $97(77.6)$ & \\
\hline Positive & $57(16.5)$ & $29(13.1)$ & $28(22.4)$ & \\
\hline Differentiation & & & & 0.750 \\
\hline Well & 47 (13.6) & $32(14.5)$ & $15(12.0)$ & \\
\hline Moderate & $230(66.5)$ & $144(65.2)$ & $86(68.8)$ & \\
\hline Poor & 69 (19.9) & $45(20.3)$ & $24(19.2)$ & \\
\hline TNM stage & & & & 0.035 \\
\hline I & $88(25.4)$ & $65(29.4)$ & $23(18.4)$ & \\
\hline II & $116(33.5)$ & $75(33.9)$ & $41(32.8)$ & \\
\hline III & $142(41.1)$ & $81(36.7)$ & $61(48.8)$ & \\
\hline $\mathrm{CRP}(\mathrm{mg} / \mathrm{L})$ & & & & $<0.001$ \\
\hline$\leq 10.5$ & $250(72.3)$ & $219(99.1)$ & $31(24.8)$ & \\
\hline$>10.5$ & $96(27.7)$ & $2(0.9)$ & $94(75.2)$ & \\
\hline $\operatorname{ALB}(g / L)$ & & & & 0.037 \\
\hline$\leq 40.5$ & $179(51.7)$ & $105(47.5)$ & $74(59.2)$ & \\
\hline$>40.5$ & $167(48.3)$ & $116(52.5)$ & $51(40.8)$ & \\
\hline PALB (mg/L) & & & & $<0.001$ \\
\hline$\leq 248$ & $161(46.5)$ & $81(36.7)$ & $80(64.0)$ & \\
\hline$>248$ & $185(53.5)$ & $140(63.3)$ & $45(36.0)$ & \\
\hline CAR & & & & $<0.001$ \\
\hline$\leq 0.3$ & $272(78.6)$ & $221(100)$ & $51(40.8)$ & \\
\hline$>0.3$ & $74(21.4)$ & $0(0)$ & $74(59.2)$ & \\
\hline
\end{tabular}

ESCC: esophageal squamous cell carcinoma; CRP: C-reactive protein; PALB: prealbumin; ALB: albumin; CPR: C-reactive protein to prealbumin ratio; CAR: C-reactive protein to albumin ratio; TNM: tumor, node, metastasis.

(39.6\% vs. $11.5 \%, P<0.001)$, ALB (25.1\% vs. $38.9 \%, P=0.002)$, and CAR $(39.0 \%$ vs. $5.4 \%, P<0.001)$ were found in our study. However, CRP, ALB, and CAR were not independent predictive indicators.

Currently, as a serum index for the assessment on nutritional status, PALB has become a research focus, with it being reported as another important biomarker for nutritional status in recent studies, which is more sensitive to malnutrition than ALB [14, 15]. Recently, Li et al. [24] reported that CPR was independently correlated with hospital mortality. Lu et al. [25] revealed that the predictive value of CPR is significantly better than other biomarkers in the recurrence of gastric cancer. However, to our knowledge, no study has assessed the prognostic role of CPR in ESCC patients so far. Additionally, the predictive value between CPR (CRP/PALB) and CAR (CRP/ALB) remains unknown. Therefore, we conducted the current study to explore the prognostic value of CPR with the optimal cut-off value in resectable ESCC patients. In our results, patients with a high level of CPR $(>0.03)$ were associated with poor CSS and OS $(\mathrm{P}<0.001)$. Even more, we found that CPR, instead of CAR, was an independent predictor for CSS and OS in multivariate analyses.

Currently, PALB, serving as an important biomarker for nutritional status, has become a research focus due to 
TABLE 2: Univariate and multivariate analyses of CSS in ESCC patients.

\begin{tabular}{|c|c|c|c|c|}
\hline & $\begin{array}{c}\text { Univariate analysis } \\
\text { HR }(95 \% \mathrm{CI})\end{array}$ & P-value & $\begin{array}{c}\text { Multivariate analysis } \\
\text { HR }(95 \% \mathrm{CI})\end{array}$ & P-value \\
\hline$\overline{\text { Age (years) }}$ & & 0.584 & & \\
\hline$\leq 60$ & 1.000 & & & \\
\hline$>60$ & $0.930(0.717-1.206)$ & & & \\
\hline Gender & & 0.530 & & \\
\hline Female & 1.000 & & & \\
\hline Male & $1.105(0.809-1.510)$ & & & \\
\hline Tumor length $(\mathrm{cm})$ & & 0.001 & & \\
\hline$\leq 3.0$ & 1.000 & & & \\
\hline$>3.0$ & $1.634(1.208-2.211)$ & & & \\
\hline Tumor location & & 0.845 & & \\
\hline Upper & 1.000 & & & \\
\hline Middle & $1.160(0.624-2.156)$ & 0.638 & & \\
\hline Lower & $1.197(0.644-2.222)$ & 0.569 & & \\
\hline Vessel invasion & & 0.003 & & \\
\hline Negative & 1.000 & & & \\
\hline Positive & $1.636(1.187-2.255)$ & & & \\
\hline Differentiation & & 0.075 & & \\
\hline Well & 1.000 & & & \\
\hline Moderate & $1.247(0.834-1.864)$ & 0.282 & & \\
\hline Poor & $1.660(1.045-2.638)$ & 0.032 & & \\
\hline $\mathrm{CRP}(\mathrm{mg} / \mathrm{L})$ & & $<0.001$ & & \\
\hline$\leq 10.5$ & 1.000 & & & \\
\hline$>10.5$ & $1.896(1.450-2.479)$ & & & \\
\hline $\operatorname{ALB}(g / L)$ & & 0.002 & & \\
\hline$\leq 40.5$ & 1.000 & & & \\
\hline$>40.5$ & $0.669(0.517-0.867)$ & & & \\
\hline PALB (mg/L) & & $<0.001$ & & \\
\hline$\leq 248$ & 1.000 & & & \\
\hline$>248$ & $0.613(0.474-0.792)$ & & & \\
\hline CPR & & $<0.001$ & & 0.008 \\
\hline$\leq 0.03$ & 1.000 & & 1.000 & \\
\hline$>0.03$ & $2.116(1.634-2.739)$ & & $1.630(1.135-2.342)$ & \\
\hline CAR & & $<0.001$ & & 0.052 \\
\hline$\leq 0.3$ & & & 1.000 & \\
\hline$>0.3$ & & & $1.485(0.997-2.212)$ & \\
\hline Adjuvant therapy & 1.000 & 0.329 & & \\
\hline No & $1.149(0.870-1.517)$ & & & \\
\hline \multicolumn{5}{|l|}{ Yes } \\
\hline TNM stage & & $<0.001$ & & $<0.001$ \\
\hline I & 1.000 & & 1.000 & \\
\hline II & $1.804(1.237-2.631)$ & 0.002 & $1.628(1.111-2.387)$ & 0.012 \\
\hline III & $3.067(2.150-4.373)$ & $<0.001$ & $2.559(1.786-3.667)$ & $<0.001$ \\
\hline \multicolumn{5}{|l|}{ BMI $(\mathrm{kg} / \mathrm{m} 2)$} \\
\hline$\geq 20$ & 1.000 & $<0.001$ & 1.000 & $<0.001$ \\
\hline$<20$ & $2.006(1.551-2.595)$ & & $1.877(1.444-2.440)$ & \\
\hline
\end{tabular}

ESCC: esophageal squamous cell carcinoma; CRP: C-reactive protein; PALB: prealbumin; ALB: albumin; CPR: C-reactive protein to prealbumin ratio; CAR: C-reactive protein to albumin ratio; TNM: tumor, node, metastasis; BMI: body mass index; CI: confidence interval; HR: hazard ratio. 

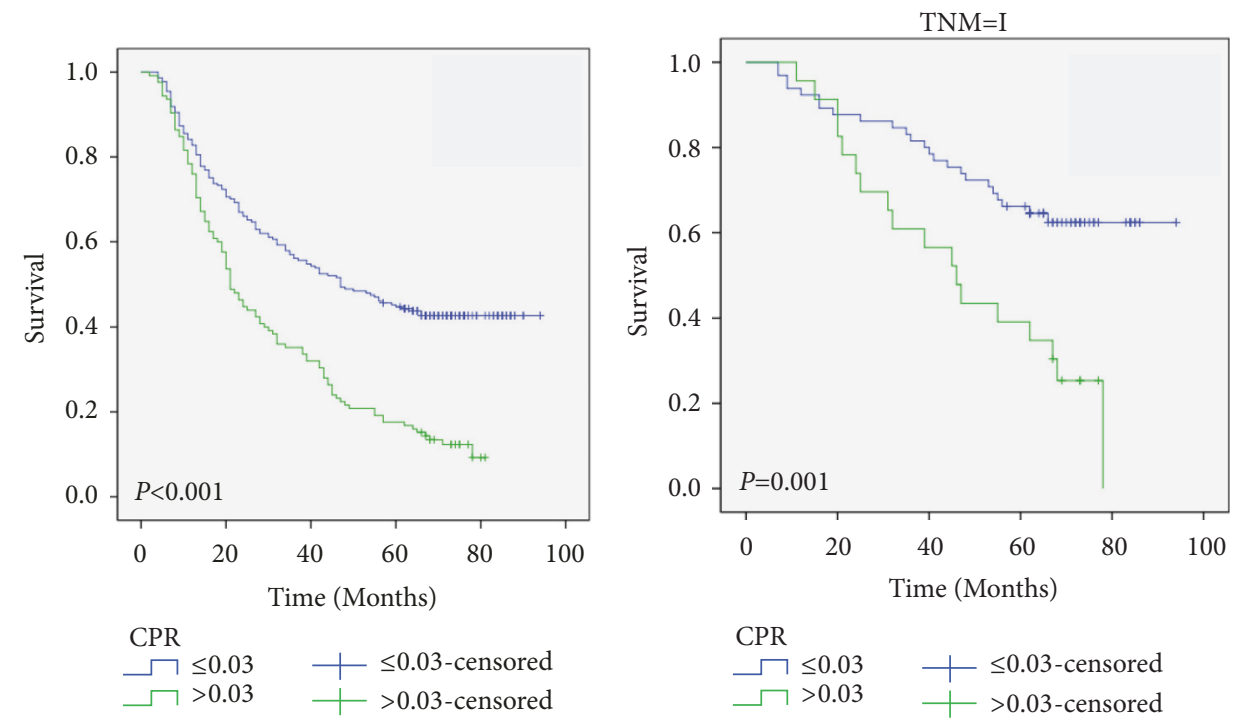

(a)

(b)
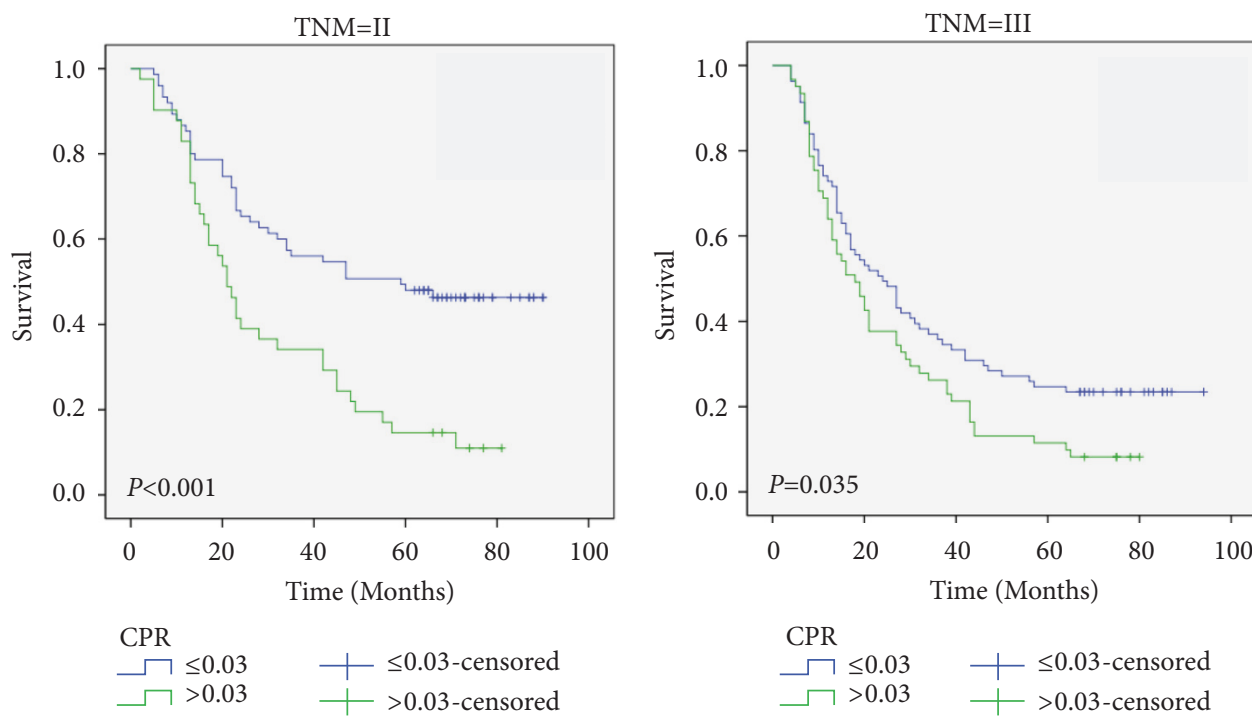

(c)

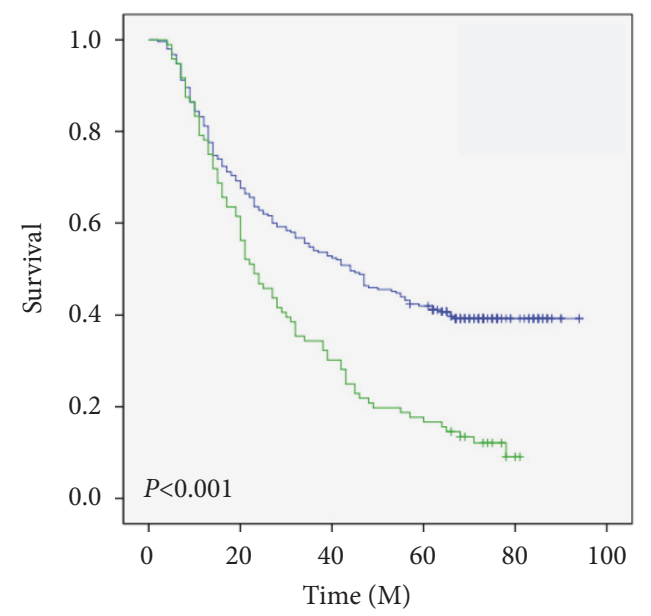

(d)

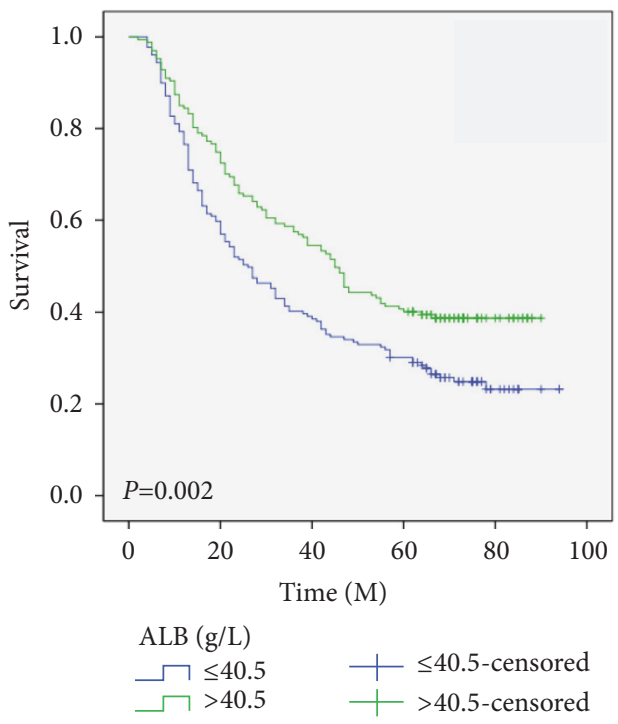
CRP (mg/L)
$\neg \leq 10.5 \quad-\leq 10.5$-censored
$\neg>10.5 \quad \longrightarrow>10.5$-censored

(e)

(f)

Figure 3: Continued. 


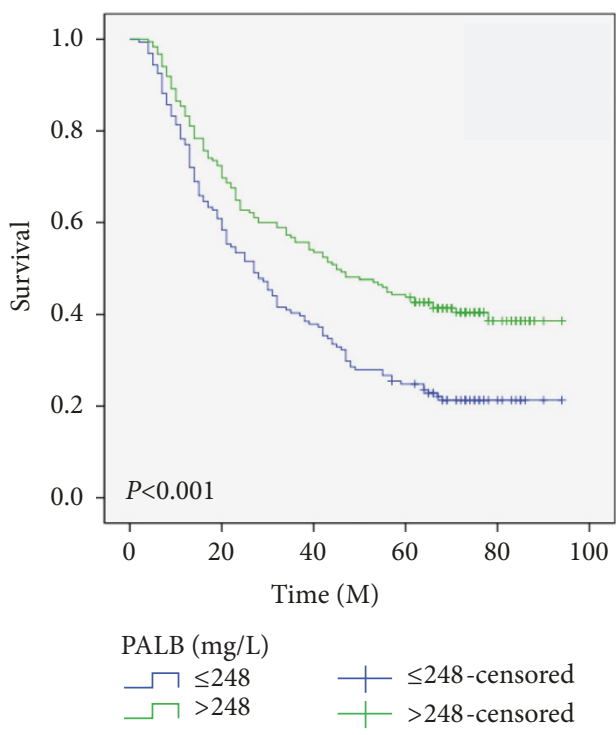

(g)

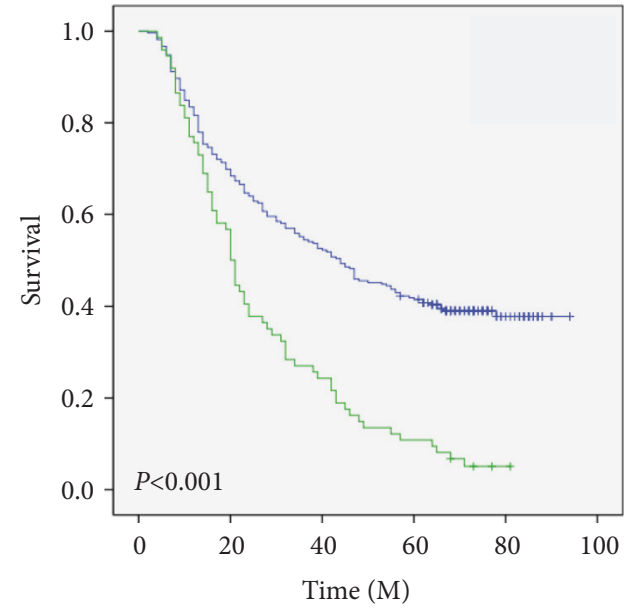

CAR

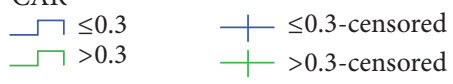

(h)

Figure 3: CSS analyses. Patients with a high level of CPR $(>0.03)$ were associated with poor CSS $(\mathrm{P}<0.001)(\mathrm{a})$. CPR was also significantly associated with CSS based on TNM stage (b-d). There were also significant differences for patients grouped by CRP (e), ALB (f), PALB (g), and CAR (h).

TABLE 3: Multivariate analyses of OS in patients with ESCC.

\begin{tabular}{llc}
\hline & HR $(95 \% \mathrm{CI})$ & P-value \\
\hline TNM stage & & \\
$\quad$ II vs. I & $1.518(1.048-2.199)$ & 0.027 \\
III vs. I & $2.386(1.685-3.379)$ & $<0.001$ \\
BMI $(\mathrm{kg} / \mathrm{m} 2)(\leq 20$ vs. $>20)$ & $1.843(1.422-2.388)$ & $<0.001$ \\
CPR $(>0.03$ vs. $\leq 0.03)$ & $1.630(1.140-2.322)$ & 0.007 \\
CAR $(>0.3$ vs. $\leq 0.3)$ & $1.474(0.992-2.189)$ & 0.055 \\
\hline
\end{tabular}

ESCC: esophageal squamous cell carcinoma; OS: overall survival; TNM: tumor, node, metastasis; BMI: body mass index; CPR: C-reactive protein to prealbumin ratio; CAR: C-reactive protein to albumin ratio; CI: confidence interval; HR: hazard ratio.

TABLE 4: Comparison of AUC areas for the prognostic factors in ESCC.

\begin{tabular}{lllc}
\hline & AUC & $95 \%$ CI & P-value \\
\hline CPR & 0.728 & $0.678-0.774$ & Reference \\
CAR & 0.702 & $0.651-0.750$ & 0.0015 \\
CRP & 0.702 & $0.651-0.750$ & 0.0008 \\
ALB & 0.573 & $0.519-0.625$ & 0.0001 \\
PALB & 0.686 & $0.635-0.735$ & 0.2161 \\
\hline
\end{tabular}

ESCC: esophageal squamous cell carcinoma; CRP: C-reactive protein; PALB: prealbumin; ALB: albumin; CPR: C-reactive protein to prealbumin ratio; CAR: $\mathrm{C}$-reactive protein to albumin ratio; AUC: area under the curve.

shorter half-life than ALB $[26,27]$. Additionally, ALB is not a nutritional biomarker if malnutrition develops in a short time. Furthermore, the weight loss that was used to define malnutrition negatively correlated with PALB, but not with ALB [15]. Therefore, PALB is a more sensitive biomarker than ALB to assess the nutritional status in patients with ESCC. It is generally recognized that CRP and PALB are both routinely tested serum enzymes in daily clinical practices, which makes them easily available. Therefore, we have firstly explored the prognostic value of CPR in patients with ESCC in the current study. Besides, it is commonly argued by plenty of researchers that CRP and PALB may be influenced by a variety of other noncancer related conditions, and the potential basis could be decreased by the CRP to PALB ratio (CPR).

Another index for assessing nutritional status was BMI. Obesity is showing a rising trend worldwide with the improvement of living standards. It had been reported that the BMI was associated with the prognosis in EC [28]. This 

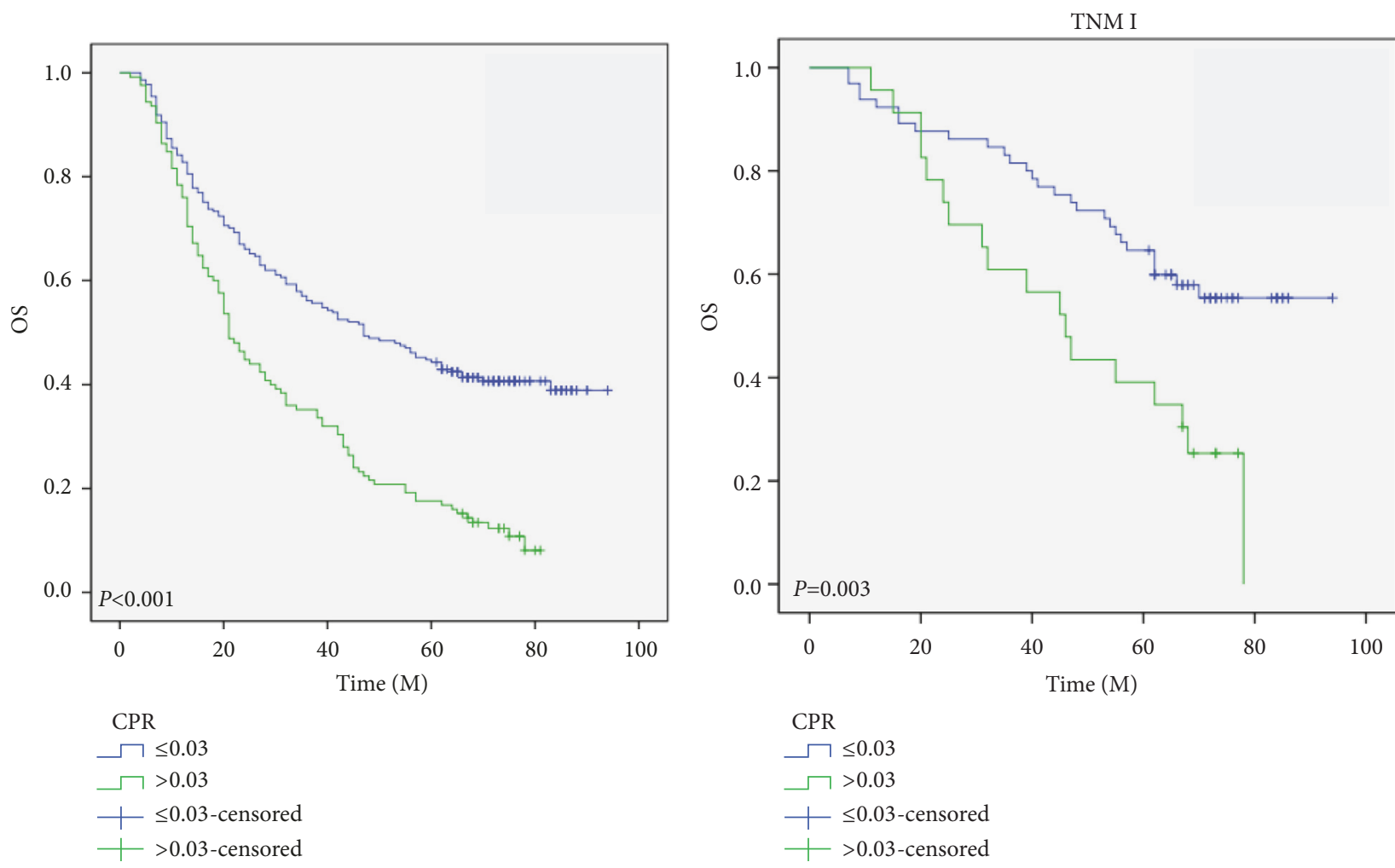

(a)

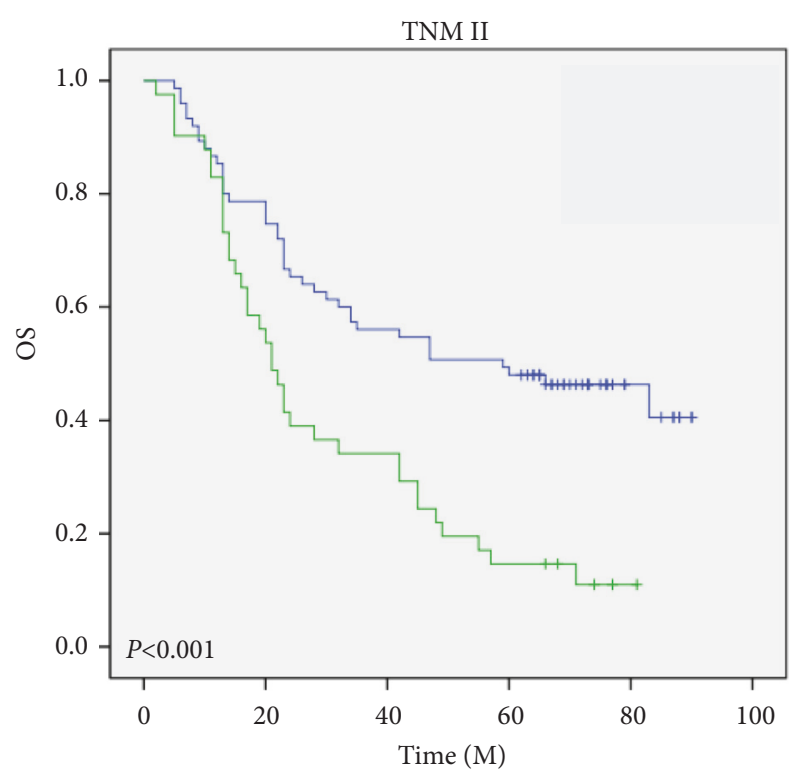

(b)

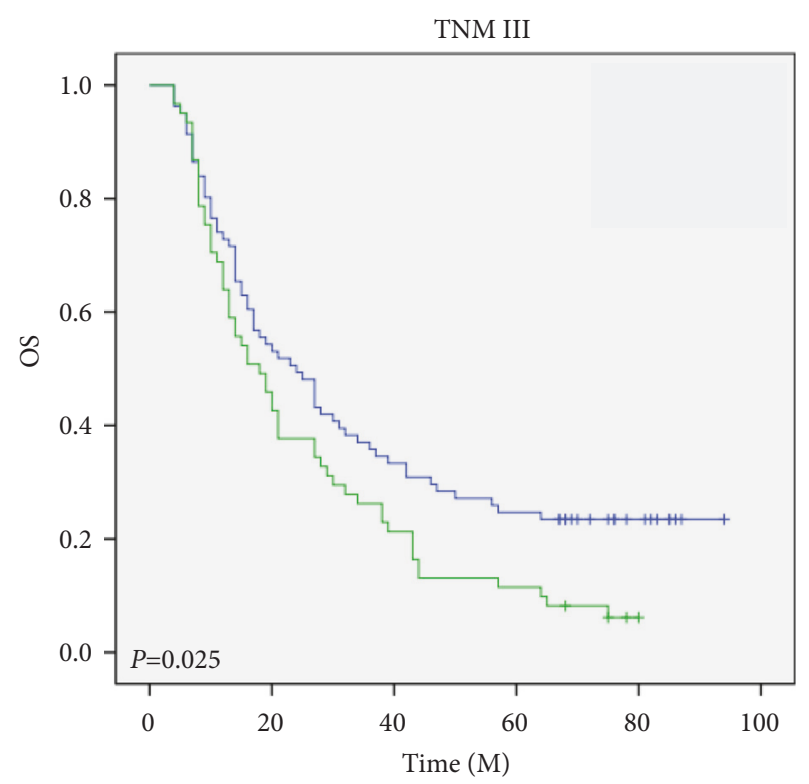

CPR

$$
\begin{aligned}
\square & \leq 0.03 \\
\square & >0.03 \\
- & \leq 0.03 \text {-censored } \\
+ & >0.03 \text {-censored }
\end{aligned}
$$

(c)

$$
\begin{aligned}
& \text { CPR } \\
& \square \leq 0.03 \\
& \square>0.03 \\
& +\leq 0.03 \text {-censored } \\
& +\square>0.03 \text {-censored }
\end{aligned}
$$

(d)

FIGURE 4: OS analyses. Patients with a high level of CPR $(>0.03)$ were associated with poor OS $(\mathrm{P}<0.001)(\mathrm{a})$. CPR was also significantly associated with OS based on TNM stage (b-d). 


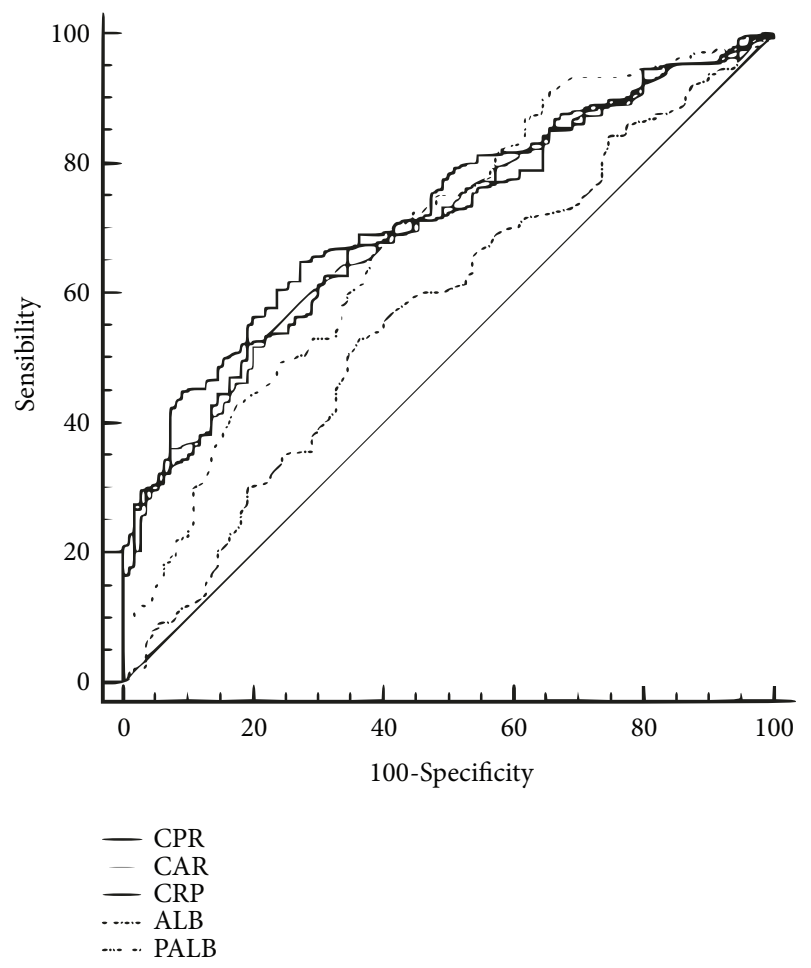

Figure 5: ROC analyses. The AUC area of the CPR (0.728) was higher than the areas of CAR (0.702), CRP (0.702), ALB (0.573), and PALB (0.686) for all the ESCC patients.

study suggested that BMI exerted a significant role in CSS and OS, with BMI being an independent factor for predicting CSS and OS in ESCC patients $(P<0.001)$.

Limitations should be acknowledged in this study. The study is mainly limited by its retrospective character and the relatively small samples in a single center. Moreover, patients who received preoperative treatment, such as chemotherapy and/or radiotherapy, were excluded, which might influence the result of this study. Moreover, it is commonly acknowledged that neoadjuvant treatment will generate a side effect on CRP, ALB, and PALB. However, neoadjuvant treatment can improve cancer prognosis for locally advanced ESCC, but not for ESCC at the early stage $[29,30]$.

\section{Conclusions}

The study is the first time for us to identify (CRP/PALB) CPR and determine its prognostic value in ESCC patients undergoing esophagectomy. Our results revealed that CPR was an effective and independent predictor in resectable ESCC patients with the optimum cut-off point of 0.03 .

\section{Data Availability}

The data used to support the findings of this study are included within the Supplementary Materials file.

\section{Conflicts of Interest}

The authors have no conflicts of interest to disclose.

\section{Authors' Contributions}

Ji-Feng Feng and Xun Yang conceived and designed the study. Ji-Feng Feng, Liang Wang, and You-Hua Jiang collected the clinical baseline characteristics and drafted the manuscript. Liang Wang carried out the follow-up. Ji-Feng Feng and Liang Wang performed the data analyses and statistical analyses. You-Hua Jiang and Xun Yang checked the data and revised the manuscript. Ji-Feng Feng and Xun Yang conceived the study and helped to draft and approve the manuscript. All authors read and approved the final manuscript.

\section{Acknowledgments}

This study was funded by the Medical Health Science and Technology Project of Zhejiang Provincial Health Commission (nos. 2018KY290 and 2019RC129 to FJF and no. 2019RC128 to WL).

\section{Supplementary Materials}

The data used to support the findings of this study. (Supplementary Materials)

\section{References}

[1] R. L. Siegel, K. D. Miller, and A. Jemal, "Cancer statistics, 2015," CA: A Cancer Journal for Clinicians, vol. 65, no. 1, pp. 5-29, 2015.

[2] J. Ferlay, H. R. Shin, F. Bray, D. Forman, C. Mathers, and D. M. Parkin, "Estimates of worldwide burden of cancer in 2008: GLOBOCAN 2008," International Journal of Cancer, vol. 127, no. 12, pp. 2893-2917, 2010.

[3] K. J. Napier, M. Scheerer, and S. Misra, "Esophageal cancer: A review of epidemiology, pathog enesis, staging workup and treatment modalities," World Journal of Gastrointestinal Oncology, vol. 6, no. 5, pp. 112-120, 2014.

[4] L. Bedenne, P. Michel, O. Bouché et al., "Chemoradiation followed by surgery compared with chemoradiation alone in squamous cancer of the esophagus: FFCD 9102," Journal of Clinical Oncology, vol. 25, no. 10, pp. 1160-1168, 2007.

[5] M. J. D. Arnal, Á. F. Arenas, and Á. L. Arbeloa, "Esophageal cancer: risk factors, screening and endoscopic treatment in Western and Eastern countries," World Journal of Gastroenterology, vol. 21, no. 26, pp. 7933-7943, 2015.

[6] A. Mantovani, P. Allavena, A. Sica, and F. Balkwill, "Cancerrelated inflammation," Nature, vol. 454, no. 7203, pp. 436-444, 2008.

[7] J. Szkandera, M. Stotz, G. Absenger et al., "Validation of Creactive protein levels as a prognostic indicator for survival in a large cohort of pancreatic cancer patients," British Journal of Cancer, vol. 110, no. 1, pp. 183-188, 2014.

[8] T. Shimura, M. Kitagawa, T. Yamada et al., "C-reactive protein is a potential prognostic factor for metastatic gastric cancer," Anticancer Reseach, vol. 32, no. 2, pp. 491-496, 2012.

[9] U. Zingg, J. Forberger, B. Rajcic, C. Langton, and G. G. Jamieson, "Association of C-reactive protein levels and long-term survival 
after neoadjuvant therapy and esophagectomy for esophageal cancer," Journal of Gastrointestinal Surgery, vol. 14, no. 3, pp. 462-469, 2010.

[10] H. Miyata, M. Yamasaki, Y. Kurokawa et al., "Prognostic value of an inflammation-based score in patients undergoing preoperative chemotherapy followed by surgery for esophageal cancer," Experimental and Therapeutic Medicine, vol. 2, no. 5, pp. 879-885, 2011.

[11] T. Kobayashi, K. Oshima, T. Yokobori et al., "Perioperative nutriture in esophageal cancer patients undergoing esophagectomy," Hepato-Gastroenterology, vol. 60, no. 126, pp. 1311-1316, 2013.

[12] X. Xu, H. Yu, W. Hu, Q. Song, and W. Mao, "A novel inflammation-based prognostic score, the C-reactive protein/albumin ratio predicts the prognosis of patients with operable esophageal squamous cell carcinoma," PLoS ONE, vol. 10, no. 9, Article ID e138657., 2015.

[13] X. Wei, F. Wang, D. Zhang et al., "A novel inflammation-based prognostic score in esophageal squamous cell carcinoma: the C-reactive protein/albumin ratio," BMC Cancer, vol. 15, no. 1, article no 350, 2015.

[14] K. Gonda, M. Shibata, Y. Sato et al., "Elevated neutrophil-tolymphocyte ratio is associated with nutritional impairment, immune suppression, resistance to S-1 plus cisplatin, and poor prognosis in patients with stage IV gastric cancer," Molecular and Clinical Oncology, pp. 1073-1078, 2017.

[15] D. Unal, O. Orhan, C. Eroglu, and B. Kaplan, "Prealbumin is a more sensitive marker than albumin to assess the nutritional status in patients undergoing radiotherapy for head and neck cancer," Wspótczesna Onkologia, vol. 3, pp. 276-280, 2013.

[16] Y. Yang, Q. Shang, Y. Yuan, X. Wu, W. Hu, and L. Chen, "Comparison of long-term quality of life in patients with esophageal cancer after ivor-lewis, mckeown, or sweet Esophagectomy," Journal of Gastrointestinal Surgery, vol. 23, no. 2, pp. 225-231, 2019.

[17] D. P. Raymond, C. W. Seder, C. D. Wright et al., "Predictors of major morbidity or mortality after resection for esophageal cancer: A society of thoracic surgeons general thoracic surgery database risk adjustment model," The Annals of Thoracic Surgery, vol. 102, pp. 207-214, 2016.

[18] H. Kato and M. Nakajima, "Treatments for esophageal cancer: a review," General Thoracic and Cardiovascular Surgery, vol. 61, no. 6, pp. 330-335, 2013.

[19] T. W. Rice, V. W. Rusch, H. Ishwaran, and E. H. Blackstone, "Cancer of the esophagus and esophagogastric junction: datadriven staging for the seventh edition of the American joint committee on cancer/international union against cancer staging manuals," Cancer, vol. 116, no. 16, pp. 3763-3773, 2010.

[20] R. L. Camp, M. Dolled-Filhart, and D. L. Rimm, "X-tile: a new bio-informatics tool for biomarker assessment and outcomebased cut-point optimization," Clinical Cancer Research, vol. 10, no. 21, pp. 7252-7259, 2004.

[21] J. Feng and Q. Chen, "Significance of the prognostic nutritional index in patients with esophageal squamous cell carcinoma," Therapeutics and Clinical Risk Management, vol. 10, pp. 1-7, 2014.

[22] H. Shimada, Y. Nabeya, S.-I. Okazumi et al., "Elevation of preoperative serum C-reactive protein level is related to poor prognosis in esophageal squamous cell carcinoma," Journal of Surgical Oncology, vol. 83, no. 4, pp. 248-252, 2003.

[23] X. Yang, Y. Huang, J. F. Feng, and J. S. Liu, "Prognostic significance of neutrophil-to-lymphocyte ratio in esophageal cancer: a meta-analysis," Onco Targets Therapy, vol. 8, pp. 789794, 2015.

[24] L. Li, L. Dai, X. Wang et al., "Predictive value of the Creactive protein-to-prealbumin ratio in medical ICU patients," Biomarkers in Medicine, vol. 11, no. 4, pp. 329-337, 2017.

[25] J. Lu, B. B. X, Z. F. Zheng et al., "CRP/prealbumin, a novel inflammatory index for predicting recurrence after radical resection in gastric cancer patients: post hoc analysis of a randomized phase III trial," Gastric Cancer, vol. 22, pp. 536-545, 2019.

[26] J. P. Geisler, G. C. Linnemeier, A. J. Thomas, and K. J. Manahan, "Nutritional assessment using prealbumin as an objective criterion to determine whom should not undergo primary radical cytoreductive surgery for ovarian cancer," Gynecologic Oncology, vol. 106, no. 1, pp. 128-131, 2007.

[27] L. T. Guerra, A. R. Rosa, R. F. Romani et al., "Serum transferrin and serum prealbumin as markers of response to nutritional support in patients with esophageal cancer," Nutricion Hospitalaria, vol. 24, pp. 241-242, 2009.

[28] S. C. Wightman, M. C. Posner, M. G. Patti et al., "Extremes of body mass index and postoperative complications after esophagectomy," Diseases of the Esophagus, vol. 30, no. 5, pp. 16, 2017.

[29] J. Shapiro, J. J. van Lanschot, M. C. Hulshof et al., "Neoadjuvant chemoradiotherapy plus surgery versus surgery alone for oesophageal or junctional cancer (CROSS): long-term results of a randomised controlled trial," The Lancet Oncology, vol. 16, pp. 1090-1098, 2015.

[30] C. Mariette, L. Dahan, F. Mornex et al., "Surgery alone versus chemoradiotherapy followed by surgery for stage I and II esophageal cancer: Final analysis of randomized controlled phase III trial FFCD 9901," Journal of Clinical Oncology, vol. 32, no. 23, pp. 2416-2422, 2014. 


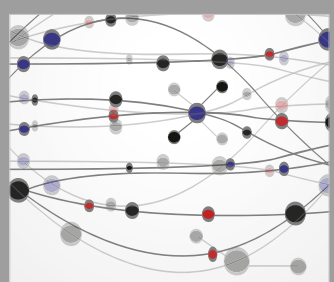

The Scientific World Journal
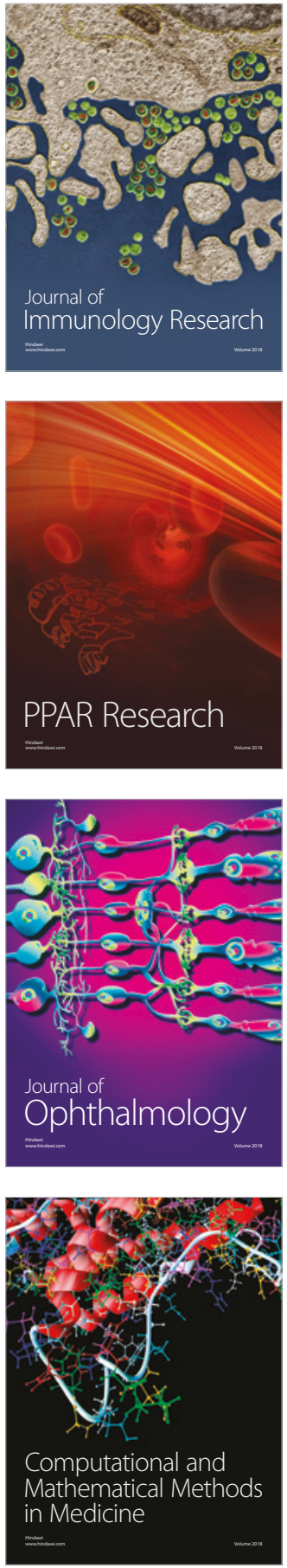

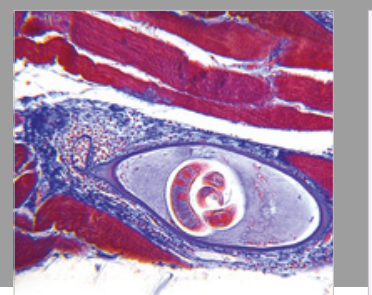

Gastroenterology Research and Practice

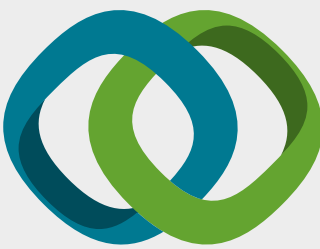

\section{Hindawi}

Submit your manuscripts at

www.hindawi.com
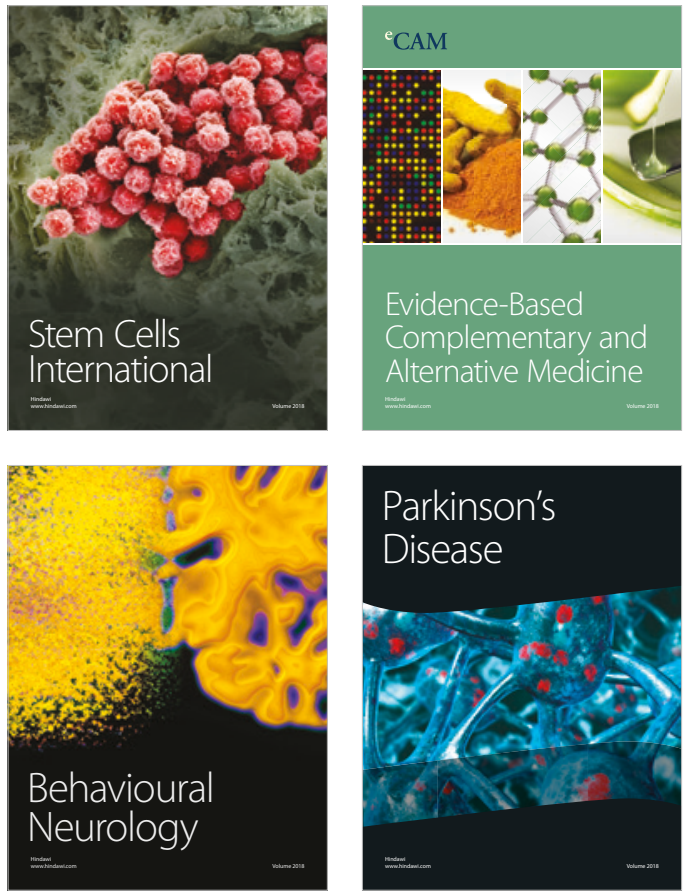

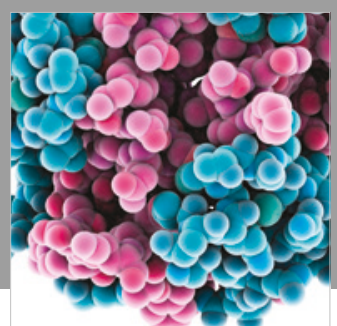

ournal of

Diabetes Research

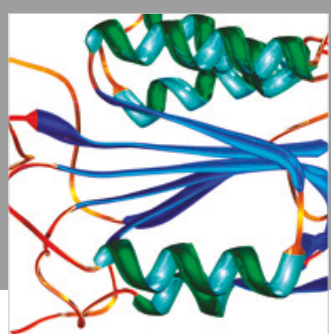

Disease Markers
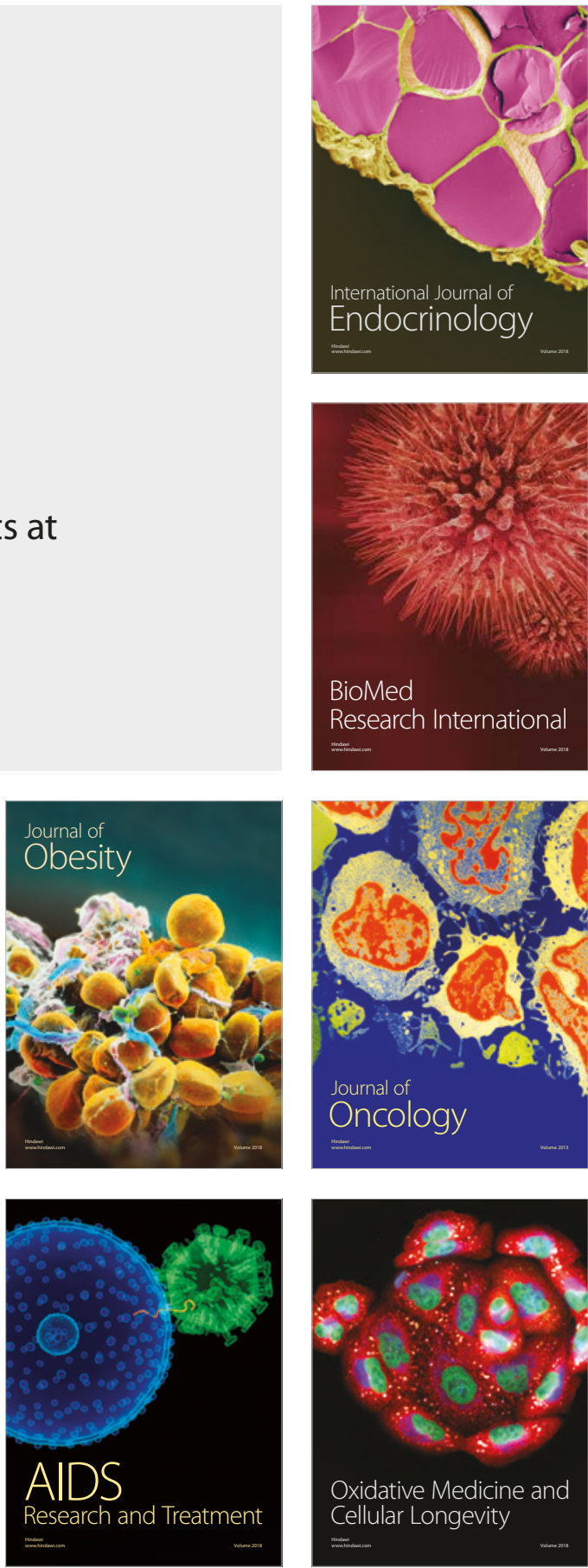